\title{
Problems of Using Information Technologies in Governmental Regulation
}

\author{
Natalia Kovaleva*, Ekaterina Filippova, Mariya Raznoglyadova, Tatiana Rudchenko
}

\author{
Saratov State Law Academy, Volskaya, 1, Saratov, 410056 Russia \\ *Corresponding author. Email: kovaleva.natalia@mail.ru
}

\begin{abstract}
Information technologies, penetrating into all spheres of society, ensure the evolution of legal regulation, including the field of government administration. The purpose of the study is to analyse the impact of technologization of government administration, government regulations and regional development and assess the impact on the development of the digital environment. The result of the study was the argumentation of the author's position regarding the need for the government regulation of the use of information technologies and artificial intelligence technologies. Conclusions of the study: analysis of trends in modernization of government administration in the context of using information technologies contributes to the formation of the information society, improving the quality of living standards through the comprehensive implementation of information technologies in government regulation, as a result of which there are effects that improve the quality of living standards and development of industrial engineering, there is also an increase in the possibility of using artificial intelligence in ensuring the industrial economy, which in its turn is one of the factors of regional development and, as a result, the most important tool for creating strong competitive advantages of the Russian state in the setting of digital environment.
\end{abstract}

Keywords: information technologies, government administration, information law, risks of using information

technology

\section{INTRODUCTION}

Nowadays, the problems of technological and legal interaction of the subjects of modern society as an information society are occurring more and more often. The development strategy of the information society in the Russian Federation emphasizes the particular importance of administrative regulation in creating the necessary pace and quality of development and functioning of the information society. Important conditions for the formation of civil society are the expansion of citizen participation in the management of the state affairs, the control strengthening over the activities of all branches of government, and the inclusion of citizens in the process of making important state decisions. The determining condition for public control activity is the openness of the authorities, since the information on their activities is the subject of analysis and evaluation of the public [1]. In the Russian doctrine, the subject of information law is defined through such a very formalized concept as "information", in contrast to the European and Anglo-American legal doctrines, which define information law through the concept of "information technology" [2-10].

The most important task in the determining of government administration in terms of the usage of information technology is providing of mass information services based on the state information resource. Unfortunately, the state and municipal bodies that own the corresponding information resource do not provide mass information services, which is due, inter alia, to the lack of appropriate technological, personnel, organizational and financial capabilities. In these cases, it would be promising to create a system that ensures interaction with non-state information services that would produce information products and provide information services based on the use of state information resources. In this regard, it is necessary to ensure legal regulation of the system of interaction between authorities and non-state information services regarding the use of state information resources and the conditions for the distribution of information products and services. In addition, it is necessary to establish the relationship between the informatization of the activities of bodies and privileges, their mutual influence, which is expressed in the administrative and legal regulation of the use of information technologies. The implementation of these technologies in public life depends mainly on two components: the availability of technological infrastructure and sufficient regulatory regulation [11].

\section{DATA AND METHODOLOGY}

When conducting the study, we collected complete information about the forms of use of information technology in government administration. 
The search for information was carried out among the scientific literature, where 21 sources were identified.

They provided information on the development and functioning of state regulation and on access to state information in Russia and foreign countries.

In addition to the scientific literature, for an in-depth study of the problem posed, the authors analysed legislative and regulatory acts, governing state regulation on access to state information as well as the procedure for digitalization of state regulation and official websites of the Government of the Russian Federation, the President of the Russian Federation, websites containing statistical data, the website of the Federal Portal of Draft regulatory legal acts of the Russian Federation

The following research methods were used:

- formal-legal - was used to identify signs and analyse the concepts of "social entrepreneurship", "legal regulation of the use of information technology";

- the method of comparative law - was used in the work when comparing the legal regulation of the use of information technology in public administration;

- a system-structural method - in accordance with which, when studying an object or phenomenon, its features are analysed as a structural element that is part of a more general concept, organizational measures have been developed to remove the barriers to the use of digital and artificial intelligence technologies in public administration; - an informational approach, according to which, when studying any object, process or phenomenon in nature and society, the most characteristic informational aspects that are most characteristic for them are identified and analysed, which substantially determine their state and development.

An independent study was conducted to study public opinion in 2016 and 2019 in a pilot sample of 45 people. Based on the findings of the survey, the authors identified a number of problem areas in the use of information technologies and artificial intelligence technologies in public administration, and measures were developed to eliminate them.

\section{RESULTS OF THE RESEARCH}

The global trend is the digitalisation of all public processes, including law, the result of digitalisation is the emergence of fundamentally new subjects and objects of law: virtual entity, virtual property [12], cryptocurrencies, blockchain technologies, cybersecurity and many others. Which, in turn, expands the possibilities of legal transformation in the process of creating new branches of law, among which one can single out information law, digital law.

The legal basis for the development of e-government has become the federal target program "Electronic Russia 2002-2010", approved by Decree of the Government of the Russian Federation of January 28, 2002 No. 65 (as amended on June 09, 2010) "On the federal target program“ Electronic Russia (2002 - 2010)“.
The state program "Information Society (2011-2020)", approved by Decree of the Government of the Russian Federation of April 15, 2014 No. 313 "On Approving the State Program of the Russian Federation" Information Society ", which contains such provisions as information and communication technologies (hereinafter referred to as ICT) in education and science, personnel for ICT, ICT in healthcare and the social sphere, ICT in culture, the development of information technology in industry, of the digital divide of the RF subjects, telecommunication infrastructure, ICT for life safety, the terms of which were modified in March 2019, and the program period "20112020" was excluded from the title as the implementation of the program was extended until 2024. An open government relies heavily on the work of e-government, the regulatory framework of which is the totality of programs, orders, resolutions, concepts adopted by the Government and the President of the Russian Federation. Based on these documents the full functioning of egovernment is made possible. As part of the development of the program and the implementation of e-government, e-governments of the Russian Federation are developed and operate. Federal Law of July 27, 2006 No. 149-FZ "On Information, Information Technologies and the Protection of Information" regulates the activities of egovernment in the regions of the Russian Federation.

When implementing the Concept of Openness of Federal Executive Bodies, Methodological Recommendations on the implementation of the principles of openness were developed, as well as Methods for Monitoring and Openness of Federal Executive Bodies, which continue to introduce the mechanism of e-government and open government. In order to improve convenience in the interaction of applicants with state bodies, multifunctional centres for the provision of state and municipal services (MFCs) are developed, which provide a range of public services to federal executive bodies, executive bodies of constituent entities of the Russian Federation and local governments.

This part of the article is based on a sociological study conducted in 2016 on the opinions of students of Saratov on e-government, after 3 years this study was repeated, in order to analyse the change in students' opinions on the functioning of e-government (fig.1). Thus, the total number of respondents amounted to 45 people, similarly to 2016.

With the help of questionnaires, a sampled population was examined (45 people) in this pilot study. This sociological study showed that out of 45 respondents surveyed, $7.1 \%$ have no idea about e-government (fig.2).

This means that these respondents do not use egovernment, compared with 2016, the percentage of young people who do not use e-government decreased by $10.7 \%$. The number of young people using the portal of state and municipal services, the electronic government information platform increased by $16.6 \%$, which means that information technologies have begun to penetrate our lives more and more, the number of students using mobile applications is increasing, as a result, the number respondents using e-government is also increasing. 


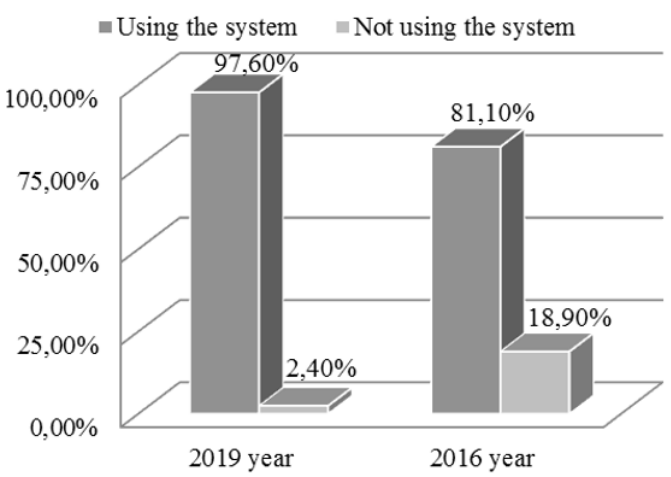

Figure 1 Using an e-government system

Student E-Government Awareness

" Awareness $\quad$ Ignorance

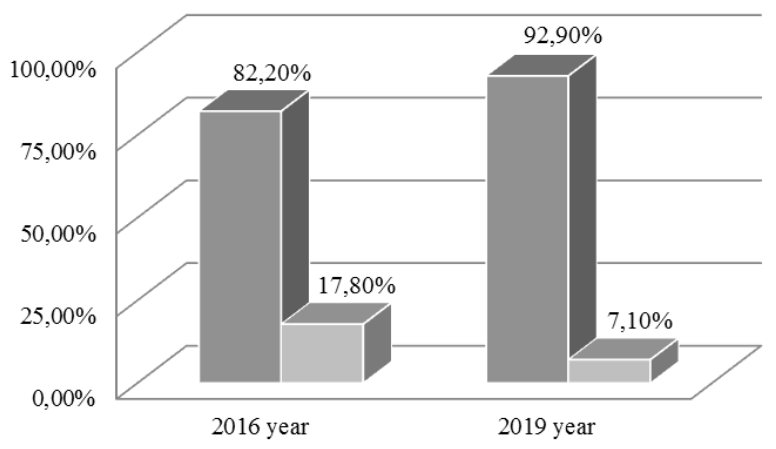

Figure 2 Student E-Government Awareness

To the question: "What are the possibilities of egovernment that are decisive for you when accessing the portal of state and municipal services?” 92.7\% (2016$70.3 \%$ ) of respondents said that they turn to the portal in order to save time (fig.3). It follows that the use of the portal of state and municipal services provides citizens with less time to engage in necessary, but not too exciting activities, while freeing up time for other priority goals. This is an conclusive proof of the need to increase the volume of digitalization of public administration.

The legal framework governing the practical issues of the formation and implementation of the information policy of the subject, allowing for the development of the information space as the basis for building the information society is under development, but may differ significantly from the results achieved; normative legal acts are adopted that regulate the procedure for creating information resources and information infrastructure, the transition of state authorities to electronic document management, the time difference between the start of the transition to electronic document management is 4-5 years, where the socio-economic development of the region plays an important role. As a result of the study, to improve organizational and legal provisions, uniform standards and methodological recommendations can be adopted on the system of interdepartmental electronic interaction of executive authorities of entities that will allow information systems to read out information as quickly as possible and process it without loss.

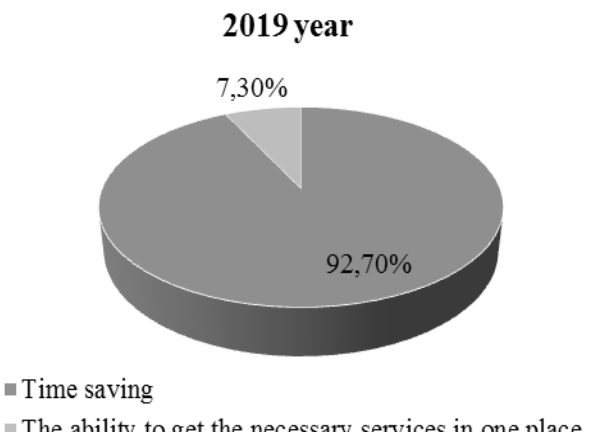

2016 year

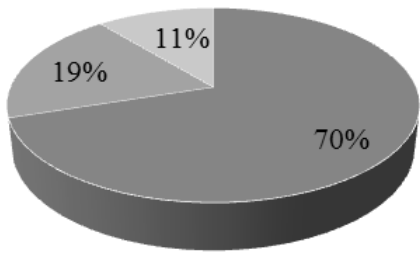

- Time saving

- The ability to get the necessary services in one place

$=$ Improving the transparency of administrative procedures

Figure 3 Possibilities of e-government

The use of information technologies in the e-government system of the region needs additional protection of users from unauthorized access, false and "malicious" information.

In addition, the human factor plays a large role in the provision of state and municipal services, additional control and supervision of the activities of officials is necessary when they provide services, including additional protection of information systems from interference in information processes that occur during the processing and receipt of information (change dates, terms).

\section{BACKGROUND}

Special government attention is required in the information sphere of society, since its development is carried out according to certain laws.

As Dobrenkov V.I. notes, the process of informatization, covering all spheres of life in our society, necessarily requires not only and not so much technical and economic, but, above all, sociological reflection and analysis of the social consequences of the general informatization of society [13].

The main information problems of modern society, according to A.P. Sukhanov, can be reduced to four interconnected sets of tasks to be solved: purely pragmatic; scientific and educational; social and humanitarian; moral and legal [14]. 
Meanwhile, the formation of the legal sphere of informatization allows us to talk about the sustainable development of all processes of informatization of society. But, as experience shows, argues G.V. Belov, the direct borrowing of foreign developments and ideologies in this area cannot lead to acceptable results, especially now, during the period of radical transformations in the country [15].

The Tunisian program for the information society, adopted at the World Summit on the Information Society on November 15, 2005, emphasizes that "the continuous development of the culture of cybersecurity should lead to increased access and enhanced trade relations, and the level of social economic development of each country are to be taken into account, as well as the developmentoriented aspects of the information society". It should be emphasized that a special place in the mechanism of information support for government administration is occupied by state information control, which existed and continues to exist in all known types and kinds of states, including ancient city states, feudal republics, totalitarian regimes and modern Western democracies. Moreover, the well-known fact that "the state, and not the entrepreneurinnovator in its garage both in America and around the world, was the initiator of the information technology revolution" [16], was at least partly a consequence of persistent efforts of the state to make its control over information, if not monopoly, then effective.

Recognizing the necessity of its existence, as well as improving the quality of information support for state policy, is neither a tribute to the domestic "imperialsovereign tradition" nor a concession to Western statism. Information control is the same inherent component of state activity as the collection of taxes or the defence of the country. The point here is not in the fact of state control over information activities, but in the quality, methods and forms of ensuring the state's information policy I. L. Bachilo [17] and J. Kurbalia [18] point to the fact of the need for the participation of governments of different states in the formation of a single information space.

We consider it possible to agree with A. V. Manoilo [19] that the objects of government administration of the information environment are all elements of information systems, networks, etc. In addition, A.V. Manoilo proposed a classification of such objects. Firstly, these are objects of a material and technical nature; they include the entire information and telecommunication infrastructure of society. The main goal of the government management of these objects is to create conditions under which the information infrastructure is steadily developing and functioning, is accessible to all and provide all opportunities for professional and communicative activities. Secondly, objects of a virtual (virtual material nature) are primarily an information resource. Among the main tasks of state regulation of these objects, we can single out control over information flows and ensuring information security. Finally, the third group of objects of government administration in terms of using information technology are objects of human nature - individuals and legal entities. Legal regulation of these objects must be built on the basis of information transparency.

It should be noted the risks arising from the use of information technology without proper government regulation. Currently, US courts and correctional institutions use algorithms to determine the "risk" of the accused, which varies from the likelihood that a person will commit another crime, to the likelihood that the accused will appear at the hearing. This algorithmic output data allows to make decisions about bail, sentencing, and parole. Each tool seeks to increase the accuracy of human decision-making, which allows better allocation of final resources. As a rule, government agencies do not write their own algorithms, but buy them from private companies. This often means that the algorithm is the property or the "black box", that is, only the owners and to a limited extent the buyer can see how the software makes decisions. There is currently no federal law that sets standards or requires testing of these tools, as the FDA does with new drugs [20].

Or the risk of social manipulation: social media, thanks to their autonomous algorithms, are very effective in targeted marketing. They know who we are, what we like, and incredibly well guess what we think. By spreading propaganda among people identified using algorithms and personal data, AI can target them and distribute any information they want in any format that they consider the most convincing - fact or fiction [21]. Any powerful technology can be used for other purposes. Today, artificial intelligence and other information technologies are used for many good purposes, including to help us make better medical diagnoses, find new ways to treat cancer and make our cars safer. Unfortunately, as the capabilities of the artificial intelligence and other information technologies expand, we will also witness that they are used for dangerous or harmful purposes. Since such technologies are developing so fast, it is vital for us to begin discussing the best ways for their positive development while minimizing their destructive potential. And one of the main areas of risk minimization is state regulation.

\section{CONCLUSION}

The promotion in our country of projects for the introduction of electronic document management in organizations, the creation of conditions for increasing trust in electronic documents, as well as the implementation of electronic identification and authentication of participants in legal relations are named among the main tasks of using information and communication technologies for the development of the social sphere, government administration system, interaction of citizens and the state in the Strategy for the Development of the Information Society in the Russian Federation for 2017-2030.

The active development of the use of information technology in the activities of public authorities of all three branches is constrained by a number of problems. E- 
government is not functioning properly. The government programs regulating the functioning of electronic parliament and electronic justice are being amended in terms of extending the implementation time due to lack of funding, socio-economic status, and technical equipment, for example, providing courts of general jurisdiction with video conferencing. After making changes to the program of implementation of the "Information Society" to extend the deadline until 2024, a number of subjects changed the development strategies of the information society. The transition to the provision of state and municipal services in electronic form, electronic interdepartmental interaction is far from complete due to the fact that information systems were created in the absence of uniform approved data formats, which, in turn, made difficult their compatibility and transfer from one format to another. So, in the course of the study of 9 constituent entities of the Russian Federation, only in one constituent entity of the Russian Federation was created a centre for the organization of information exchange in electronic form between participants in information interaction, which provides for the compatibility of formats of various databases of executive authorities. When analysing the electronic interaction of public authorities, it was revealed that information on the websites of executive authorities is not always updated, often there is no regulatory framework, and there is no separate platform for electronic government of the constituent entity. When drawing up passports of programs for the development of the information society, executive authorities of the constituent entities of the Russian Federation pay special attention to the insufficient dissemination of skills in using information and telecommunication technologies at work and everyday life, while the programs provide for the implementation of activities, the issue of booklets, videos on the use of electronic government services, using videos as an example on the website www.gosuslugi.ru. An analysis of the regional legislation of the constituent entities of the Russian Federation showed that the regional legal framework governing the practical issues of the formation and implementation of the subject's information policy, which provides for the development of the information space as the basis for building the information society, is under development, but may differ significantly from the results achieved; normative legal acts are adopted that regulate the procedure for creating information resources and information infrastructure, the transition of state authorities to electronic document management, the time difference between the start of the transition to electronic document management is $4-5$ years, where the socio-economic development of the region plays an important role. As a result of the study, to improve organizational and legal provisions, uniform standards and methodological recommendations can be adopted on the system of interdepartmental electronic interaction of executive authorities of entities that will allow information systems to read information as quickly as possible and process it without loss. The use of information technologies in the e-government system of the region needs additional protection of users from unauthorized access, false and "malicious" information. In addition, the human factor plays a large role in the provision of state and municipal services, additional control and supervision of the activities of officials is necessary when they provide services, including additional protection of information systems from interference in information processes that occur during the processing and receipt of information (change dates, terms).

\section{REFERENCES}

[1] Malko A.V., Isakov N.V., Subochev V.V. Legal policy in the settlement of lobbyism. Saratov, 2003.

[2] Barta J., Markiewiez R. Main problems of computer law. Warshawa, 1993

[3] Junker A., Benecke M. Computer Law. 2nd edition Baden-Baden, 2000; Information law 2000: Perspectives for the next decade / On behalf of The German Society for Law and Computer Science and Information. by Alfred Büllesbauch u. Tomas Heymann. Cologne, 2001.

[4] Kugelmann D. The information status of the burger: foundations and basic administrative structures of individual rights to access administrative information. Tubingen: Mohr, 2001. pp. 285, 302-305.

[5] Druey J.N. Information as an object of law: drafting a foundation. P. 42-43.

[6] Zalauf R. Information quality. A contribution to the journalistic quality debate from the perspective of information law: Dissertation / Approved upon application by Prof. Dr. Rolf H. Weber. Zurich: Schulthess Juristische Medien AG, cop. 2000. pp. 3233.

[7] E. Clarke, O. Grumberg, S. Jha, et al., Counterexample-guided abstraction refinement, in: E.A. Emerson, A.P. Sistla (Eds.), Computer Aided Verification, Springer, Berlin, Heidelberg, 2000, pp. 154-169. DOI: https://doi.org/10.1007/10722167_15

[8] Bainbridge David I. Introduction to computer law. 4.ed. Harlow; London; New York: Longman, 2000.

[9] Rowland D., Macdonald E. Information technology law. 2. ed. London; Sydney: Cavendish publishing, cop. 2000 .

[10] Smith Graham J.H. Internet law and regulation / By Graham J.H. Smith and contributors from Bird \& Bird: Simon Chalton et al. 3. ed., reprint. London, 2002. 
[11] N.N. Kovaleva, A.Yu. Sokolov, K.S. Krotov. The establishment of digital law as the regulator of access to governmental information aiding the regional development/ Proceedings of the 1st International Scientific Conference "Modern Management Trends and the Digital Economy: from Regional Development to Global Economic Growth" (MTDE 2019) DOI: https://www.atlantis-press.com/proceedings/mtde19/125907618; DOI: https://doi.org/10.2991/mtde19.2019.89.

[12] Kovaleva N.N. Zhirnova N.A. Filimonova M.V. The Virtual Property under the Legislation of the Russian Federation: Present State and Development Trends/ Proceedings of the 1st International Scientific Conference "Modern Management Trends and the Digital Economy: from Regional Development to Global Economic Growth" (ISTDE 2019) DOI: https:/www.atlantis-press.com/proceedings/iscde19/125924712; DOI: https://doi.org/10.2991/iscde19.2019.158.

[13] Dobrenkov V.I. Social and humanitarian problems of informatisation and information security of modern global society. M., 2001

[14] Sukhanov A.P. On the legal support of information activities // Law and legal regulation in the system of sustainable social development: conference proceedings (April 5-6, 1994, Novosibirsk). Novosibirsk:

Publishing House of the Russian Academy of Sciences, Siberian Branch, 1994. P. 120-122
[15] Belov G.V. Information Law // Materials of the All-Russian Scientific Seminar "Social and Human Sciences in Russia: Personnel, Organization, Orientation" (December 1993). M., 1993. P. 4-7.

[16] Castellls M. The state and Technology: Policy: A Comparative Anlysis of U.S. Strategic Defense Initiative, Informatics Policy in Brasil, and Electronics Policy in China. Berkeley, 1988.

[17] Bachilo I.L. Information law: a textbook. 2nd ed., Revised. and add. M., 2011.S. 377; P .173-174.

[18] Courbalia J. Internet Governance. M., 2010.

[19] Manoilo A.V. State information policy in special conditions. Information Security Doctrine. M., 2003.

[20] Jason Tashea. Courts Are Using AI to Sentence Criminals. That Must Stop Now/ DOI:

https://www.wired.com/2017/04/courts-using-aisentence-criminals-must-stop-now/ (access date 28.02.2020).

[21]Bernard Marr. Is Artificial Intelligence Dangerous? 6 AI Risks Everyone Should Know About// DOI: https://www.forbes.com/sites/bernardmarr/2018/11/19/i s-artificial-intelligence-dangerous-6-ai-risks-everyoneshould-know-about/\#621a55382404 (access date 28.02.2020). 